\title{
THEMATIC PAPER \\ International efforts at implementing and advancing the recovery model
}

\author{
Anthony O. Ahmed, ${ }^{1}$ Peter F. Buckley ${ }^{2}$ and P. Alex Mabe $^{3}$
}

Assistant Professor, Department of Psychiatry and Health Behavior, Georgia Health Sciences University, Augusta GA 30912,USA, email aahmed@ GA 30912, USA, em
georgiahealth.edu

2Professor of Psychiatry and Dean of the Medical College of Georgia, Georgia Health Sciences University

${ }^{3}$ Professor, Department of Psychiatry and Health Behavior Georgia Health Sciences University
For almost a century the medical model has been the overarching framework for mental healthcare but since the 1980s it has been challenged by a consumer/survivor movement. Central to this revolution is the recovery model, which suggests that mental illness is only one of many facets of the life of an individual with mental illness, and that a full, meaningful life is possible despite illness (Anthony, 1993). The medical model emphasises the role of symptomatic improvements and functional status, and considers recovery as an 'outcome' or 'end state', at which point symptoms are remitted and community functioning is restored. In contrast, the recovery model underscores hope, empowerment, the self-management of illness and some aspects of community functioning, such as social support and role functioning, which operate in a non-linear fashion throughout the recovery journey.

The advent of recovery was partly driven by dissatisfaction with the traditional medical model, which many consumers, family members, advocates and practitioners have viewed as fostering a gloomy picture of clinical outcomes in severe mental illnesses. The recovery model was historically fuelled by consumers'/survivors' views that traditional systems fostered disability, alienation, oppression and marginalisation (Jacobson \& Curtis, 2000). In contrast, the recovery model promises self-determination, shared decision-making, community involvement, advocacy, decreasing stigma and discrimination, and a more hopeful picture of outcomes for individuals with psychiatric illnesses.

Although recovery has begun to permeate mental healthcare systems, there has been little effort to compare and contrast recovery-oriented systems cross-nationally. The current article is a snapshot of systems transformations and the implementation of recovery across countries. The recovery model has wielded its influence in mental health systems in North America, Europe, New Zealand, Australia and Japan. Efforts at transforming national systems to recovery-oriented approaches have generally followed examples set in the USA. In some cases individual countries have incorporated unique elements into the recovery model. A full review of the international advancements of recovery would have been overly lengthy; thus, we chose to focus on countries that have experienced the most remarkable systems transformation. We begin with the USA and contrast efforts there with advances in the UK and New Zealand.

\section{Systems transformation in the USA}

Systems transformation in North America has been driven by consumer voices and political movements that sought to address glaring needs in the delivery of mental health services. In the USA, the recovery model received a substantial boost with the publication of the US Surgeon General's report on mental health and the activities of the New Freedom Commission (Hogan, 2003). The Surgeon General's report made recommendations consistent with recovery, including requiring recovery-based treatment practices, shared decision-making, self-help services, advocacy and consumer-led programmes. The Commission task force was charged by executive order to evaluate mental healthcare in the USA and offer recommendations. In its final report, the task force recommended a transformation of the nation's mental healthcare system to a recovery-oriented approach, focused on decreasing stigma, building resilience and coping, and fostering partnerships between consumers, families and practitioners. Since its political mandate, state legislatures and mental health systems have adopted a 'recovery vision' in service delivery. Further, mental health organisations have endorsed the recovery approach, including the American Psychiatric Association, the American Psychological Association, the Veterans Affairs Healthcare System, and the United States Psychiatric Rehabilitation Association (USPRA).

Some US states-Arizona, Georgia, Pennsylvania and Washington - have incorporated peer support into their reimbursable services, and Georgia and Arizona have even developed credentialing processes for peer specialists. As the recovery model evolved in the USA, it became heavily influenced by psychosocial rehabilitation, due to the contributions of service providers who viewed recovery as consistent with their practice (O'Hagan, 2004). Self-help programmes for psychiatric illnesses, including the Family to Family Programs of the National Alliance of the Mentally Ill (NAMI), have emerged in the USA and are recognised as useful adjuncts to traditional treatments. The consumer movement maintains its political roots in the activities of advocacy organisations, including NAMI, the National Mental Health Association (NMHA) 
and the State Protection and Advocacy Centers. The activities of these organisations include disseminating information about mental illness and recovery as part of efforts to decrease the stigma attached to mental illness.

\section{Systems transformation in the UK}

The recovery model has also made headway into care systems in Europe, most notably in the UK, although it remains in its infancy compared with efforts in North America and New Zealand. The Department of Health's National Service Framework for Mental Health has established standards for service systems in the UK that are consistent with recovery, including consumer and family involvement, non-discrimination and choices that promote independence. The introduction of the recovery approach in the UK has led to actions in the jurisdictions. The Scottish government established the National Programme for Improving Mental Health and Well-Being, which had the aims of disseminating information about mental health, fostering recovery in people who have experienced psychiatric illnesses, and eliminating stigma and discrimination due to mental illness. The National Institute for Mental Health in England (2005) has established 12 principles of recovery-based care that parallel the guidelines of the US-based Substance Abuse and Mental Health Services Administration (SAMHSA) for recovery-oriented care. These principles relate to self-management, community integration and responsiveness, and emphasise people's strengths and wellness.

A number of recovery-based self-management programmes have emerged in the $\mathrm{UK}$, and these serve as the psychiatric equivalents of the 'expert patient' initiatives for chronic medical conditions. These include: the Hearing Voices Network; the Safe, Holistic, Integrated Recovery Environment (SHIRE); and the TIDAL model (Davidson, 2005). Similar to efforts in North America, self-help and peer/mutual support programmes are currently being incorporated into the mental health system in the UK. These involve organisations such as Rethink Mental Illness (formerly the National Schizophrenia Fellowship), Together for Mental Well-Being, Clients and Professionals in Training and Learning (CAPITAL), Peer2Peer, and Borough-Wide User Forum (BWUF). Unlike in the USA, accredited peer support training and certification are provided by only a few organisations, such as Reading Resource, and the Nottingham University/Making Waves collaboration.

\section{Systems transformation in New Zealand}

The recovery movement appeared early in New Zealand (O'Hagan, 2004). The New Zealand government established a Mental Health Commission in 1996 to offer recommendations for a National Mental Health Strategy and to oversee its implementation. The Commission produced the Blueprint for Mental Health Services in New Zealand (Mental Health Commission New Zealand, 1998), which included recommendations for transforming the mental healthcare service into a recoveryoriented system. Its recommendations emphasised curbing or reversing the effects of the discrimination experienced by minority groups. In contrast to the recovery model in Europe and North America, which viewed recovery as an individual process, the New Zealand view underscored the role of social processes that may be associated with recovery, such as ending stigma and discrimination, and increased connectedness with cultural groups (O’Hagan, 2004).

The individual and society rather than the individual alone are responsible for promoting recovery. Thus, systems transformation in New Zealand, as reflected in the Blueprint, has focused on promoting the recovery of cultural and social groups such as the Maori and Pacific people, cultural sensitivity, citizenship, ending stigma and discrimination, ensuring that services are readily available to minority groups, and accommodating the views of service users on mental illness and coping.

Systems transformation in New Zealand has also extended to how mental health providers are trained. In 2001, the Mental Health Commission published its 'recovery competencies'. The document required that mental health training be transformed. New Zealand appears to be ahead of other countries with regard to requiring recoverybased mental health education. Although there have been efforts at recovery education in the USA (e.g. Peebles et al, 2009), recovery education is not currently mandated at the national level. In New Zealand, as in the USA, peer support programmes have emerged, for example Mind and Body Learning and Development, and the New Zealand Bipolar Network.

\section{Conclusions}

The recovery model has made headway into service systems in the USA, the UK and New Zealand through the influence of consumer voices and political mandates. A full review of all service systems implementing recovery is beyond the scope of this article, but we have reviewed steps that have been taken in a few countries. Whereas the UK adopted the American conception of recovery, New Zealand's brand of systems transformation has additionally focused on transformation of the community context in which recovery occurs, by addressing stigma and discrimination. It has also chosen to depart from an exclusively individualistic notion of recovery in favour of one that incorporates collectivist attitudes and behaviours as part of recovery. Although other countries not reviewed here, such as Ireland, the Netherlands, Italy and Australia, have also embarked on forms of systems transformation, the recovery approach has yet to be formally implemented in most nations. The adoption of that approach in care systems in Asian, African and Middle Eastern nations would be of particular interest, given the sociological aspects of 
the experience of psychiatric symptoms (Harrison et al, 2001). It may be that sociological context will be just as crucial to the adoption and advancement of recovery and subsequent systems transformation in those nations.

\section{References}

Anthony, W. A. (1993) Recovery from mental illness: the guiding vision of the mental health service system in the 1990s. Psychosocial Rehabilitation Journal, 16, 11-23.

Davidson, L. (2005) Recovery, self-management and the expert patient - changing the culture of mental health from a UK perspective. Journal of Mental Health, 14, 25-35.

Harrison, G., Hopper, K., Craig, T., et al (2001) Recovery from psychotic illness: a 15- and 25-year international follow-up study. British Journal of Psychiatry, 178, 506-517.

Hogan, M. F. (2003) New Freedom Commission report. The President's new Freedom Commission: recommendations to transform mental health care in America. Psychiatric Services, 54 1467-1447.
Jacobson, N. \& Curtis, L. (2000) Recovery as policy in mental health services: strategies emerging from the States. Psychiatric Rehabilitation Journal, 23, 333-341.

Mental Health Commission New Zealand (1998) Blueprint for Mental Health Services in New Zealand: How Things Need To Be. Available at http://www.mhc.govt.nz/sites/mhc.govt.nz/files/ publications/1998/BLUEPRINT1998.PDF (accessed December 2011).

National Institute for Mental Health in England (2005) NIMHE Guiding Statement on Recovery. Available at http://www. psychminded.co.uk/news/news2005/feb05/nimherecovstatement. pdf (accessed October 2010)

O'Hagan, M. (2004) Guest editorial. Recovery in New Zealand: lessons for Australia? Australian e-Journal for the Advancement of Mental Health, 3. Available at http://www. familymentalhealthrecovery.org/conference/handouts/ Workshop \% 2010/OHagan \% 201 \% 20Recovery \% 20in \% 20NZ.pdf (accessed October 2010).

Peebles, S. A., Mabe, P.A., Fenley, G., et al (2009) Immersing practitioners in the recovery model: an educational program evaluation. Community Mental Health Journal, 45, 239-245.

\title{
THEMATIC PAPER \\ Implementing recovery in mental health services
}

\section{RECOVERY}

\author{
Jed Boardman ${ }^{1}$ and Geoff Shepherd ${ }^{2}$
}

${ }^{1}$ Consultant/Senior Lecturer in Social Psychiatry, South London and Maudsley NHS Trust, London, UK, email jed.boardman@ centreformentalhealth.org.uk 2Recovery Programme Lead, Centre for Mental Health, London, UK

\begin{abstract}
The ideas of 'recovery' arise from the experiences of people with mental health problems. The recovery approach emerged in the North American civil rights and consumer and survivor movements from the 1970s onwards. It is concerned with social justice, individual rights, citizenship, equality, freedom from prejudice and discrimination. In this paper we discuss a project in England that has examined how mental health services may be transformed to be more supportive of recovery and the implications that this has for professional practice.
\end{abstract}

The ideas that are subsumed under the heading of 'recovery' are not new: they have their roots in the history of psychiatry (Davidson et al, 2010). Their recent history specifically reflects the intellectual output and lived experience of people with mental health problems, particularly psychoses. The contemporary roots of recovery ideas also lie in the civil rights and consumer and survivor movements that emerged in North America from the 1970s onwards. In this, people were declaring that their symptoms and incapacities need not permanently impede their achievement of personally valued life goals, and not only did mental health services need to change to recognise the legitimacy of these objectives, but also a social transformation was necessary to deal with the stigma and exclusion that are still commonly experienced by people with mental health problems in most societies (Frese $e t$ al, 2009).

\section{What is recovery?}

Recovery can be seen as a set of ideas and principles derived from the experiences of people with mental health problems and is associated with a movement calling for social justice, individual rights, citizenship, equality, freedom from prejudice and discrimination. When we talk about 'recovery' nowadays we are not necessarily talking about 'clinical recovery' (symptom reduction) but rather the process of helping people to live a life 'beyond illness' - that is, the recovery of a meaningful life, with or without symptoms. This is usually known as 'personal' or 'social' recovery (Slade, 2009).

Analysis of the accounts of people who have direct experience of mental health problems suggests that three concepts are central to recovery (Repper \& Perkins, 2003; Shepherd et al, 2008). These are: hope (sustaining motivation and supporting expectations of an individually fulfilled life), agency (recovering a sense of personal control) and opportunity (using circumstances to gain 